\title{
Tracing the Geographical Origin of Rice Based on Mineral Elements and GSA-SVM
}

\author{
Na Wang ${ }^{1}$, Dongjie Zhang ${ }^{2,3 *}$ and Jinming Liu ${ }^{1}$ \\ ${ }^{1}$ College of Electrical and Information, Heilongjiang Bayi Agricultural University, \\ Daqing 163319, China \\ ${ }^{2}$ College of Food Science, Heilongjiang Bayi Agricultural University, Daqing, \\ 163319, China \\ ${ }^{3}$ Key Laboratory of Agro-Products Processing and Quality Safety of Heilongjiang \\ Province, Heilongjiang Bayi Agricultural University, Daqing 163319, China \\ 1yaya588588@163.com, 2*byndzdj@126.com,3jinmingliu2008@126.com
}

\begin{abstract}
To explore the feasibility of tracing the geographical origin of rice which influenced by mineral elements, ICP-MS is used to analyze the mineral content of rice samples from five areas: Fangzheng, Panjing, Wuchang, Yuanqu and Gongzhuling. The obtained sample data is traced to the geographical origin by the GSA-SVM algorithm. The result showed that the mineral content of rice samples from different regions had their own characteristics. The accuracy of the discrimination of the sample data in the five regions using the prediction model generated by the GSA-SVM algorithm is between $88.4615 \% \sim 98.0769 \%$. Therefore, the mineral element analysis technology and GSA-SVM model can be used to identify the origin of rice, which provides a stable and efficient method for identifying and tracing the origin of rice.
\end{abstract}

Keywords: Gravitational Search Algorithm (GSA), Support Vector Machine (SVM), Mineral element geographical origin traceability

\section{Introduction}

Rice is the necessary food in our daily life. With the improvement of living standards, most people are concerned about the rice's quality increasingly. It has been transformed from "full up" to "eat satisfied". Due to the influence of geographical climate, water, soil and other environmental factors, the nutritional quality and commercial value of rice vary significantly from place to place. Some illegal traders have affected the healthy development of the rice market by unqualified. In recent years, more and more researchers in various countries have paid great attention to the protection of agricultural products [1][2][3]. Domestic and foreign scholars have studied the origin traceability of mineral element fingerprints in agricultural products, such as tea [4], olive oil [5], wine [6], soybean [7], fruit juice and other fields [8]. Studies have been conducted on the origin traceability of rice by using the content of mineral elements. For example, Pracha [9], there is the determination of mineral element content and the application of principal component analysis combined with discriminant analysis method,

Article history:

Received (February 3, 2020), Review Result (March 5, 2020), Accepted (April 6, 2020) 
successfully identified 31 kinds of Thai fragrant rice from the rice samples of France, India, Italy and Japan. Ariyama [10] identified rice samples from Japan, the United States, China and Thailand by the methods of SIMCA, LDA and KNN to generate discriminant models based on eight mineral elements in rice. Zhang Yue [11] identified rice from three main areas in Songyuan city which in Jilin province by combining mineral elements with Fisher's discriminant method, and the accuracy was higher than others.

The mineral elements in rice are taken from the surrounding environment where it grows, and it is affected by the local geology, soil, climate and other environmental factors. As a result, rice grown in different regions has different mineral fingerprint characteristics. At the same time, the mineral elements in rice are more stable than those contained in other components, which are not affected by the storage time and mode. Therefore, by analyzing the composition of mineral elements in rice and the content of each component, the rice in different regions can be distinguished. However, different rice varieties, fertilization and other factors have a certain impact on the accuracy of origin traceability [12][13][14], therefore, how to solve these unstable factors is one of the difficulties to improve the accuracy of origin traceability of rice.

Because of the fertile soil, abundant sunshine and good water quality in the three northeastern provinces, the rice produced here are of high quality and commercial value. Therefore, a number of national geographic indication rice are produced here, such as wuchang rice in Heilongjiang province, founder rice, Xiangshui rice, Jiansanjiang rice, Panjin rice and Hengren rice in Liaoning province, Yanbian rice and Meihe rice in Jilin province, and so on. In this study, 154 samples from five regions of the three provinces are used as experimental materials. ICP-MS is used to analyze the different characteristics of mineral elements in different samples. GSA-SVM (GSA combined with SVM) is used to establish discriminant analysis. The origin of rice in different provinces or regions of the same province is identified by mineral elements, which provided a new idea for the establishment of rice traceability system.

\section{Materials and method}

\subsection{Materials}

In 2015, the experiment selected the 154 rice samples in the Liao, Kyrgyzstan, Black three provinces, including 35 rice samples from Panjin City, Liaoning Province, 27 rice samples from Gongzhuling City, Jilin Province, 31 rice samples from Wuchang City, Heilongjiang Province, 33 rice samples from the Park and 27 rice samples from Fangzheng County, Heilongjiang Province.

\subsection{Test instruments}

ICP-MS7700 Agilent Corporation, USA; DHG-9123A electric heating constant temperature blast drying oven Shanghai Jinghong Experimental Equipment Co., Ltd.; VP-32 Rice Mill and Rice Huller Sasaki Corporation of Japan; LM-3100 High Speed Universal Crusher Beijing Botong Ruihua Instruments Co., Ltd.;Milli-Q Ultra-pure Water Machine Millipore Corporation, USA.

\subsection{Method}


At harvest time, rice samples are collected from the field, numbered, dried and threshed, then uniformly hulled, hulled, milled, rinsed and dried in the laboratory, and then superfine crushed [15]. Each powdered rice sample with a certain quality is weighed by an electronic balance, and put into the digestive tube, adding a suitable amount of concentrated nitric acid and hydrochloric acid, which is then heated up for digestion in a microwave digestion apparatus. The obtained sample solution is washed out with ultra-pure water and brought to a constant volume. ICP-MS is used to measure the content of 52 minerals in the rice samples, including $\mathrm{Na}, \mathrm{Mg}, \mathrm{Al}, \mathrm{K}, \mathrm{Ca}, \mathrm{Sc}, \mathrm{V}, \mathrm{Cr}, \mathrm{Mn}, \mathrm{Fe}, \mathrm{Co}, \mathrm{Ni}, \mathrm{Cu}, \mathrm{Zn}, \mathrm{As}, \mathrm{Se}, \mathrm{Rb}, \mathrm{Sr}, \mathrm{Y}, \mathrm{Mo}, \mathrm{Ru}$, Rh, Pd, Ag, Cd, Sn, Sb, Te, Cs, Ba, La, Ce, Pr, Nd, Sm, Eu, Gd, Tb, Dy, Ho, Er, Tm, Yb, Lu, $\mathrm{Hf}, \mathrm{Ir}, \mathrm{Pt}, \mathrm{Au}, \mathrm{Tl}, \mathrm{Pb}$, Th and $\mathrm{U}$.

\subsection{Model construction}

\subsubsection{SVM algorithm}

SVM [16][17][18][19] is a new generation of learning algorithm. It mainly constructs a hyperplane to make samples of the same type fall on the same side of the hyperplane, so as to achieve the purpose of classification. SVM is based on the principle of structured minimization (both training error and testing error), which can provide good generalization performance in pattern classification, and has outstanding advantages for small sample, nonlinear and high-dimensional data processing. The characteristic of this study is that the data of mineral element content of rice samples are nonlinear and high dimensional. SVM algorithm is originally designed for binary classification. This paper tries to distinguish Fangzheng rice, Panjin rice, Wuchang rice, Yuanqu rice and Gongzhuling rice by one-versusrest method. Its method is to design an SVM model between samples of any two types of rice and construct a total of $10 \mathrm{SVM}$. When the rice samples are classified by all SVM, the category with the highest score is the category to which the rice samples belong.

(1) Segmentation of data sets. The data of 154 rice samples analyzed by ICP-MS were divided into two parts, one for the training set and one for the prediction set.

(2) Normalized preprocessing of rice sample data. It uses the formula is:

$$
f: x \rightarrow y=\frac{x-x \min }{x \max -x \min }
$$

$\mathrm{x}, \mathrm{y}$ is vectors which in $\mathrm{N}$-dimensional space; $\mathrm{xmin}=\min (\mathrm{x})$; $\mathrm{xmax}=\max (\mathrm{x})$. It can round up the rice training set and the prediction set sample data to $[0,1]$. This can improve the accuracy of the prediction.

(3) Training and prediction. SVM classifier is used to train the rice sample data in the training set; Use the training model to predict the rice sample data in the prediction set and obtain the prediction label of the category; the prediction labels are compared with the data in the category labels, and finally the discrimination correctness rate is obtained.

In the study, the choice of different kernel function types and parameters has a great influence on the accuracy of the classification. It needs to determine the type of the kernel function and the penalty parameter $\mathrm{c}$ and the kernel function parameter g. After many experiments, it was finally determined that the RBF kernel function was used as the kernel function of the prediction model, and the classification effect was the best. In order to avoid over-learning and less learning state, after step 2, the heuristic optimization algorithm GSA is used to optimize the penalty parameter $\mathrm{c}$ and the kernel function parameter $\mathrm{g}$ of the SVM algorithm, thus solving the problem of selecting parameters by experience. 


\subsubsection{GSA algorithm}

GSA [20] algorithm regards all searching particles as a group of objects with mass moving in space. In the solution space, each particle will be affected by the gravitational attraction of other particles, and the acceleration will move to the direction of maximum mass, it approaching the optimal solution of the optimization problem. GSA achieves optimal information sharing through the interaction of gravitational forces between particles. Without the influence of external environmental factors, GSA can also achieve global optimization of the problem.

The optimization process of penalty parameter $\mathrm{c}$ and kernel function parameter $\mathrm{g}$ of SVM using GSA is as follows:

(1) Initialize the algorithm related parameters such as position, acceleration, number of iterations, and population size.

(2) The fitness value of each rice sample particle is calculated, and the classification prediction error rate is taken as the optimized objective function value. Before calculating the fitness value of each rice sample particle, it is necessary to judge whether it crosses the boundary.

(3) The inertial mass $M(t)$ and gravitational constant $G(t)$ of rice sample particles are calculated. Formula (3) represents the mass $\mathrm{M}_{\mathrm{i}}(\mathrm{t})$ of sample particle $\mathrm{Xi}$ at time $\mathrm{t}$ and formula (4) represents the gravitational constant $\mathrm{G}(\mathrm{t})$.

$$
\begin{gathered}
\boldsymbol{m}_{\boldsymbol{i}}(\boldsymbol{t})=\frac{\boldsymbol{f i t}_{\boldsymbol{i}}(\boldsymbol{t})-\boldsymbol{w o r s t}(\boldsymbol{t})}{\boldsymbol{b e s t}(\boldsymbol{t})-\boldsymbol{w o r s t}(\boldsymbol{t})} \\
M_{i}(t)=\frac{m_{i}(t)}{\sum_{j=1}^{N} m_{j}(t)} \\
G(t)=G_{0} \times e^{-a t / T}
\end{gathered}
$$

In formula (2), fit $(t)$ and $m_{i}(t)$ represent the fitness value and mass of sample particle $X_{i}$ at time $\mathrm{t}$; best $(\mathrm{t})$ and worst $(\mathrm{t})$ represent the best and worst fitness solutions at time $\mathrm{t}$; in formula (4), $\mathrm{G}_{0}$ takes the value of 100 at time $\mathrm{t}$, and $\alpha$ takes the value of 20 , and $\mathrm{T}$ is the maximum number of iterations.

(4) The sum of forces acting on the sample particles is calculated. Formula (5) represents the sum of the forces on the $\mathrm{K}$ dimension at time $\mathrm{t}$.

$$
F_{i}^{k}(t)=\sum_{j=1, j \neq i}^{N} \operatorname{rand}_{j} F_{i j}^{k}(t)
$$

In formula (5), $F_{i j}^{k}(t)$ represents the gravitational attraction of rice sample particle $X_{\mathrm{j}}$ at time $t$ under the particle $X_{i}$ located in $\mathrm{K}$ dimension. The calculation formula of $F_{i j}^{k}(t)$ is as shown in equation (6).

$$
F_{i j}^{k}(t)=G(t) \frac{M_{p t}(t) \times M_{a j}(t)}{R_{i j}(t)+\varepsilon}\left(x_{j}^{k}(t)-x_{i}^{k}(t)\right)
$$

In formula (6), $R_{\mathrm{ij}}(t)$ represents the Euclidean distance between the particle $X_{i}$ and the particle $\mathrm{X}_{\mathrm{j}}$, and $\varepsilon$ represents a small constant.

(5) Location update. Calculate the acceleration and velocity of each particle and update the position of the particle.

(6) Return to step 2 until the termination condition is met. 
(7) At the end of the iteration, the optimal solution is assigned to SVM's penalty parameter c and kernel function parameter g respectively, and SVM is used for rice sample data training and prediction.

\section{Results and discussion}

\subsection{Analysis on the difference of mineral content in rice samples}

ICP-MS method is used to measure 52 mineral elements in 154 rice samples from five producing areas including Fangzheng, Panjin, Wuchang, Yuanqu and Gongzhuling. Every sample is tested by three times. In this experiment, Ge, In and Bi are selected as internal standard elements. Some data of mineral content of rice in different regions (excluding elements below the detection limit in $1 / 2$ of the rice samples) is shown in Table 1 . The result showed that the mineral content of rice samples from different regions had their own characteristics. The contents of $\mathrm{Zn}, \mathrm{Rb}, \mathrm{Ag}$ and $\mathrm{Au}$ in Fangzheng rice samples are the highest, while the contents of $\mathrm{Na}$ and $\mathrm{Fe}$ are the lowest. Au is not detected in Panjin, Wuchang, Zhongyuan and Gongzhuling. The contents of $\mathrm{Na}, \mathrm{Ca}, \mathrm{Ni}$ and $\mathrm{Sr}$ in Panjin rice samples are the highest, and the contents of $\mathrm{Mg}, \mathrm{Mn}$ and $\mathrm{Zn}$ are the lowest. The content of $\mathrm{Al}, \mathrm{Mn}, \mathrm{Cu}$ and Mo in Wuchang rice samples is the highest, and the content of $\mathrm{K}$ is significantly lower than that in other regions. The content of $\mathrm{Y}$ in the rice samples in Yuanqu is the highest, and the contents of $\mathrm{Ca}$ and $\mathrm{Mo}$ are the lowest. The contents of $\mathrm{Mg}, \mathrm{K}$ and $\mathrm{Fe}$ in Gongzhuling rice samples are significantly higher than those in other areas.

According to [Table 1]: the elements ( $\mathrm{Al}, \mathrm{Fe}, \mathrm{Ag}$ ) are in these five The coefficient of variation of the region is large, while the coefficients of variation of $\mathrm{Na}$ elements are only in the Fangzheng area, the values are 1.08 and 2.55 respectively. The coefficients of variation of $\mathrm{Cr}$ and Ni elements in Panjin area are large, the values are 2.19 and 5.69 respectively. As mentioned, some elements vary widely between regions and within regions, and the mineral elements of the rice samples are closely related to the region of origin.

Table 1. Mineral element content of rice in different regions $/ \mu \mathrm{g} / \mathrm{g}$

\begin{tabular}{|c|c|c|c|c|c|c|}
\hline Element & Index & Fangzheng & Panjin & Wuchang & Yuanqu & Gongzhuling \\
\hline \multirow{2}{*}{$\mathrm{Na}$} & Content & $\begin{array}{c}2.7136 \pm 2.935 \\
4\end{array}$ & $8.1704 \pm 4.6622$ & $4.2613 \pm 2.1004$ & $3.8657 \pm 1.2453$ & $6.1489 \pm 2.4358$ \\
\hline & $\begin{array}{l}\text { Variation- } \\
\text { coefficient }\end{array}$ & 1.08 & 0.57 & 0.49 & 0.32 & 0.40 \\
\hline \multirow{2}{*}{$\mathrm{Mg}$} & Content & \begin{tabular}{|c|}
$235.5671 \pm 40$. \\
8116
\end{tabular} & \begin{tabular}{|c|}
$180.7283 \pm 21.4$ \\
816
\end{tabular} & $\begin{array}{c}194.3999 \pm 43.69 \\
05\end{array}$ & \begin{tabular}{|c|}
$223.7619 \pm 26.63$ \\
45
\end{tabular} & $365.1920 \pm 95.9373$ \\
\hline & $\begin{array}{l}\text { Variation- } \\
\text { coefficient }\end{array}$ & 0.17 & 0.12 & 0.22 & 0.12 & 0.26 \\
\hline \multirow{2}{*}{$\mathrm{Al}$} & Content & $\begin{array}{c}29.9081 \pm \\
26.6831 \\
\end{array}$ & $\begin{array}{c}30.8433 \pm \\
29.1984 \\
\end{array}$ & $\begin{array}{c}34.7001 \pm \\
26.1432 \\
\end{array}$ & $\begin{array}{c}19.8462 \pm \\
22.4333 \\
\end{array}$ & $\begin{array}{c}10.7184 \pm \\
7.6289\end{array}$ \\
\hline & $\begin{array}{l}\text { Variation- } \\
\text { coefficient }\end{array}$ & 0.89 & 0.95 & 0.75 & 1.13 & 0.71 \\
\hline \multirow{2}{*}{$\mathrm{K}$} & Content & $\begin{array}{c}621.7604+73 \\
.3343 \\
\end{array}$ & $\begin{array}{c}681.3250 \pm \\
56.5148 \\
\end{array}$ & $\begin{array}{c}587.2058 \pm \\
85.8852 \\
\end{array}$ & $\begin{array}{c}726.7355 \pm \\
74.9940\end{array}$ & $\begin{array}{c}1050.9041 \pm \\
215.0174 \\
\end{array}$ \\
\hline & $\begin{array}{l}\text { Variation- } \\
\text { coefficient }\end{array}$ & 0.12 & 0.08 & 0.15 & 0.10 & 0.20 \\
\hline $\mathrm{Ca}$ & Content & $\begin{array}{c}69.7815 \pm \\
9.1864\end{array}$ & $\begin{array}{c}106.4007 \pm \\
53.8702\end{array}$ & $\begin{array}{c}75.8960 \pm \\
14.0270\end{array}$ & $\begin{array}{c}67.9209 \pm \\
15.3329\end{array}$ & $\begin{array}{c}100.0248 \pm \\
20.8025\end{array}$ \\
\hline
\end{tabular}




\begin{tabular}{|c|c|c|c|c|c|c|}
\hline & $\begin{array}{l}\text { Variation- } \\
\text { coefficient }\end{array}$ & 0.13 & 0.51 & 0.18 & 0.23 & 0.21 \\
\hline \multirow{2}{*}{ V } & Content & $\begin{array}{c}0.0047 \pm \\
0.0037\end{array}$ & $\begin{array}{c}0.0138 \pm \\
0.0137\end{array}$ & $\begin{array}{c}0.0148 \pm \\
0.0069\end{array}$ & $\begin{array}{c}0.0144 \pm \\
0.0076\end{array}$ & $0.0073 \pm 0.0033$ \\
\hline & $\begin{array}{l}\text { Variation- } \\
\text { coefficient }\end{array}$ & 0.78 & 0.99 & 0.46 & 0.53 & 0.45 \\
\hline \multirow{2}{*}{$\mathrm{Cr}$} & Content & $\begin{array}{c}0.0903 \pm \\
0.0453\end{array}$ & $\begin{array}{c}0.2369 \pm \\
0.5179\end{array}$ & $\begin{array}{c}0.0577 \pm \\
0.0238\end{array}$ & $\begin{array}{c}0.0497 \pm \\
0.0138\end{array}$ & $0.2194 \pm 0.2508$ \\
\hline & $\begin{array}{l}\text { Variation- } \\
\text { coefficient }\end{array}$ & 0.5 & 2.19 & 0.41 & 0.28 & 1.14 \\
\hline \multirow{2}{*}{$\mathrm{Mn}$} & Content & $\begin{array}{c}11.8853 \pm \\
2.4628\end{array}$ & $\begin{array}{c}7.1302 \pm \\
2.0249 \\
\end{array}$ & $\begin{array}{c}13.8817 \pm \\
2.8034\end{array}$ & $\begin{array}{c}8.4873 \pm \\
0.9199\end{array}$ & $\begin{array}{c}11.8162 \pm \\
4.4464\end{array}$ \\
\hline & $\begin{array}{l}\text { Variation- } \\
\text { coefficient }\end{array}$ & 0.21 & 0.28 & 0.2 & 0.11 & 0.38 \\
\hline \multirow{2}{*}{$\mathrm{Fe}$} & Content & $\begin{array}{c}4.5694 \pm \\
2.0169 \\
\end{array}$ & $\begin{array}{r}8.1383 \pm \\
13.2069 \\
\end{array}$ & $\begin{array}{c}5.2132 \pm \\
3.7928 \\
\end{array}$ & $\begin{array}{c}6.2254 \pm \\
3.9310 \\
\end{array}$ & $\begin{array}{c}12.1105 \pm \\
10.8963\end{array}$ \\
\hline & $\begin{array}{l}\text { Variation- } \\
\text { coefficient }\end{array}$ & 0.44 & 1.62 & 0.73 & 0.63 & 0.90 \\
\hline \multirow{2}{*}{ Co } & Content & $\begin{array}{r}0.061 \pm \\
0.0405 \\
\end{array}$ & $\begin{array}{c}0.0039 \pm \\
0.0026 \\
\end{array}$ & $\begin{array}{c}0.0039 \pm \\
0.0019 \\
\end{array}$ & $\begin{array}{c}0.0095 \pm \\
0.0024 \\
\end{array}$ & $0.0061 \pm 0.0019$ \\
\hline & $\begin{array}{l}\text { Variation- } \\
\text { coefficient }\end{array}$ & 0.67 & 0.67 & 0.49 & 0.25 & 0.32 \\
\hline \multirow{2}{*}{$\mathrm{Ni}$} & Content & $\begin{array}{c}0.2172 \pm \\
0.1187 \\
\end{array}$ & $\begin{array}{r}2.7357 \pm \\
15.5690 \\
\end{array}$ & $\begin{array}{c}0.1641 \pm \\
0.1065 \\
\end{array}$ & $\begin{array}{c}0.1985 \pm \\
0.1148 \\
\end{array}$ & $0.2007 \pm 0.1114$ \\
\hline & $\begin{array}{l}\text { Variation- } \\
\text { coefficient }\end{array}$ & 0.55 & 5.69 & 0.65 & 0.58 & 0.55 \\
\hline \multirow{2}{*}{$\mathrm{Cu}$} & Content & $\begin{array}{c}2.1254 \pm \\
0.3742 \\
\end{array}$ & $\begin{array}{c}1.9363 \pm \\
0.7799 \\
\end{array}$ & $\begin{array}{c}2.1845 \pm \\
0.6087 \\
\end{array}$ & $\begin{array}{c}1.7953 \pm \\
0.4389 \\
\end{array}$ & $1.7170 \pm 0.5640$ \\
\hline & $\begin{array}{l}\text { Variation- } \\
\text { coefficient }\end{array}$ & 0.18 & 0.4 & 0.28 & 0.24 & 0.33 \\
\hline \multirow{2}{*}{$\mathrm{Zn}$} & Content & $\begin{array}{c}13.2466 \pm \\
1.3814\end{array}$ & $\begin{array}{c}9.8454 \pm \\
1.7247\end{array}$ & $\begin{array}{c}11.8915 \pm \\
1.2098\end{array}$ & $\begin{array}{c}11.0782 \pm \\
1.4239\end{array}$ & $\begin{array}{c}12.3469 \pm \\
1.9785\end{array}$ \\
\hline & $\begin{array}{l}\text { Variation- } \\
\text { coefficient }\end{array}$ & 0.1 & 0.18 & 0.1 & 0.13 & 0.16 \\
\hline \multirow{2}{*}{ As } & Content & $\begin{array}{c}0.1382 \pm \\
0.0359\end{array}$ & $\begin{array}{c}0.1250 \pm \\
0.0215\end{array}$ & $\begin{array}{c}0.1146 \pm \\
0.0495\end{array}$ & $\begin{array}{c}0.1456 \pm \\
0.0148\end{array}$ & $0.1126 \pm 0.0317$ \\
\hline & $\begin{array}{l}\text { Variation- } \\
\text { coefficient }\end{array}$ & 0.26 & 0.17 & 0.43 & 0.10 & 0.28 \\
\hline \multirow{2}{*}{$\mathrm{Rb}$} & Content & \begin{tabular}{|c}
$1.6451 \pm 0.88$ \\
55 \\
\end{tabular} & $\begin{array}{c}0.5923 \pm 0.41 \\
05 \\
\end{array}$ & $1.3954 \pm 0.6835$ & $1.1365 \pm 0.1259$ & $0.5776 \pm 0.3411$ \\
\hline & $\begin{array}{l}\text { Variation- } \\
\text { coefficient }\end{array}$ & 0.54 & 0.69 & 0.49 & 0.11 & 0.59 \\
\hline \multirow{2}{*}{$\mathrm{Sr}$} & Content & \begin{tabular}{|c}
$0.1261 \pm 0.09$ \\
8 \\
\end{tabular} & \begin{tabular}{|c|}
$0.2024 \pm 0.06$ \\
53 \\
\end{tabular} & $0.1356 \pm 0.1483$ & $0.1127 \pm 0.0211$ & $0.1817 \pm 0.0422$ \\
\hline & $\begin{array}{l}\text { Variation- } \\
\text { coefficient }\end{array}$ & 0.78 & 0.32 & 1.09 & 0.19 & 0.23 \\
\hline \multirow{2}{*}{$\mathrm{Y}$} & Content & 0 & $\begin{array}{c}0.0012 \pm 0.00 \\
70 \\
\end{array}$ & 0 & $1.0507 \pm 0.1477$ & 0 \\
\hline & $\begin{array}{l}\text { Variation- } \\
\text { coefficient }\end{array}$ & 0 & 5.92 & 0 & 0.14 & 0 \\
\hline Mo & Content & $\begin{array}{c}0.4927 \pm 0.11 \\
96\end{array}$ & $\begin{array}{c}0.4342 \pm 0.06 \\
90\end{array}$ & $0.5105 \pm 0.1016$ & $0.0001 \pm 0.0001$ & $0.3011 \pm 0.0816$ \\
\hline
\end{tabular}




\begin{tabular}{|c|c|c|c|c|c|c|}
\hline & $\begin{array}{c}\text { Variation- } \\
\text { coefficient }\end{array}$ & 0.24 & 0.16 & 0.2 & 1.18 & 0.27 \\
\hline \multirow{3}{*}{$\mathrm{Pd}$} & Content & $\begin{array}{c}0.1813 \pm 0.01 \\
81\end{array}$ & $\begin{array}{c}0.1644 \pm 0.01 \\
82\end{array}$ & $0.1621 \pm 0.0201$ & $0.1724 \pm 0.0190$ & $0.1584 \pm 0.0133$ \\
\cline { 2 - 7 } & $\begin{array}{c}\text { Variation- } \\
\text { coefficient }\end{array}$ & 0.1 & 0.11 & 0.12 & 0.11 & 0.08 \\
\hline \multirow{3}{*}{$\mathrm{Ag}$} & Content & $\begin{array}{c}0.0077 \pm 0.01 \\
51\end{array}$ & $\begin{array}{c}0.0048 \pm 0.01 \\
54\end{array}$ & $0.0037 \pm 0.0051$ & $0.0030 \pm 0.0053$ & $0.0025 \pm 0.0010$ \\
\cline { 2 - 7 } & $\begin{array}{c}\text { Variation- } \\
\text { coefficient }\end{array}$ & 1.96 & 3.22 & 1.35 & 1.79 & 0.40 \\
\hline \multirow{3}{*}{$\mathrm{Au}$} & Content & $\begin{array}{c}0.0047 \pm 0.00 \\
75\end{array}$ & 0 & 0 & 0 & 0 \\
\cline { 2 - 7 } & $\begin{array}{c}\text { Variation- } \\
\text { coefficient }\end{array}$ & 1.61 & 0 & 0 & 0 & 0 \\
\hline
\end{tabular}

*Note: The value of content items in tables is expressed by mean $X \pm$ standard deviation.

\subsection{Discriminant analysis}

\subsubsection{Setting of relevant parameters}

In order to investigate the feasibility of the discriminant method, this paper selects rice samples from three provinces of Liaoning Province, Jilin Province and Heilongjiang Province, as well as rice samples from similar areas of the same province (Wuchang, Fangzheng, and Yuanqu), and samples of rice from five producing areas. Set about 2/3 of each rice sample to the training sample set, a total of 102 training samples, and the remaining about $1 / 3$ of the samples are prediction sets, a total of 52 samples. The GSA algorithm is used to optimize the relevant parameters of the SVM model to improve the prediction rate. The relevant parameters are set as follows: the size of the population is 20 , the maximum number of iterations is 30, the upper and lower limits of the objective function parameters are 100 and 0.01 , the dimension of the independent variable is 2 , the gravitational force G0 is 100, and the value of $\alpha$ is 20 . The best parameter results corresponding to the best prediction model are: the penalty parameter $\mathrm{c}$ is 54.5047 , and the kernel function parameter $\mathrm{g}$ is 0.0375258 . The parameter optimization process is shown in [Figure 1].

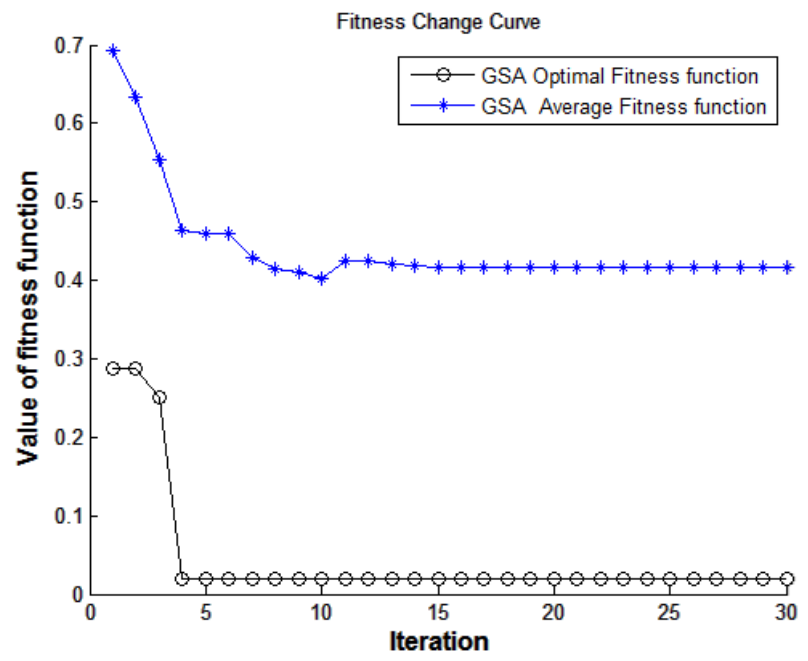

Figure 1. Fitness change curve 
In the process of optimization, the GSA algorithm converges very fast, and the population tends to be optimal in the fourth iteration. At the same time, from the perspective of average fitness, the change of the optimal solution is obvious at the beginning, and it tends to be gentle after the fourth iteration. The reason is that as time goes by, the universal gravitational constant will become smaller as the age of the universe increases. The gravitational resultant force of the sample particles becomes smaller, and the convergence speed becomes slower.

\subsubsection{Result analysis}

The best parameters generated by GSA are used for SVM training, and the trained SVM prediction model is obtained to predict and analyze the test set. The result of a test is shown in [Figure 2]. In order to verify the generalization ability of GSA-SVM model, training samples are not added to the prediction set. The calculation method of accuracy is accuracy $=$ the number of samples correctly classified by prediction / the number of samples in prediction set.

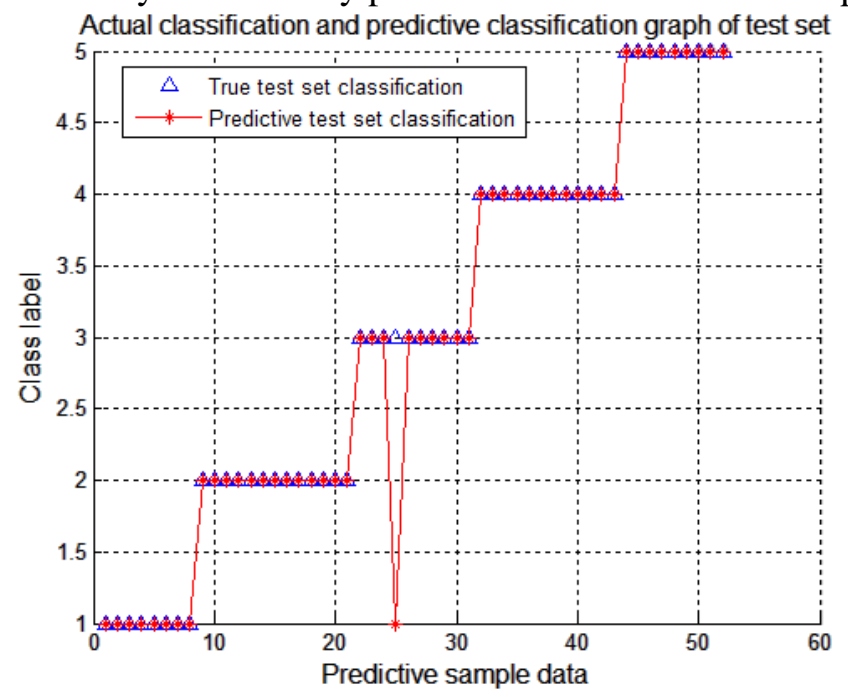

Figure 2. Actual classification and predictive classification graph of test set

As showed by [Figure 2], there are 52 predicted rice sample data, of which 8 samples belong to category 1,13 samples belonging to category 2,10 samples belonging to category 3 , 12 samples belonging to category 4 and 9 samples belonging to category 5 . The dimensions of the test sample matrix are 42 , which are 42 mineral contents of rice samples in Table 1. After discriminating by GSA-SVM prediction model, one sample data of category 3 is misjudged and the accuracy rate is $98.0769 \%$. After many tests, the best discriminant accuracy is $98.08 \%$, and the worst discriminant accuracy is $88.46 \%$. This indicates that it is feasible to use mineral content and GSA-SVM for origin traceability.

In order to test the performance and efficiency of the prediction model generated by the GSA-SVM algorithm in the origin traceability, the prediction model generated by Grid-SVM and PSO-SVM algorithm is used to compare the prediction accuracy and the running time respectively: in the grid algorithm The value range of $c$ is the smallest $2^{\wedge}(-2)$, the maximum is $2^{\wedge}(4)$, the step of $\mathrm{c}$ is 0.5 , the minimum value of $\mathrm{g}$ is $2^{\wedge}(-4)$, and the maximum value is $2^{\wedge}(4)$, $\mathrm{g}$ The stepping is 0.5 . In the PSO algorithm, the local search capability parameter $\mathrm{c} 1$ is 1.5 , the global search capability c2 is 1.7 , the maximum evolutionary number is 200 , and the population number is 20. The operating environment is Win7 64-bit operating system, the CPU is Intlel(R) Core(TM) i7-4790, and the memory is 8GB. Use the MATLAB R2012b and 
Libsvm-3.1 toolbox. Each algorithm runs 50 times. The accuracy and running time of the prediction models of different algorithms are shown in [Figure 3] and [Figure 4].

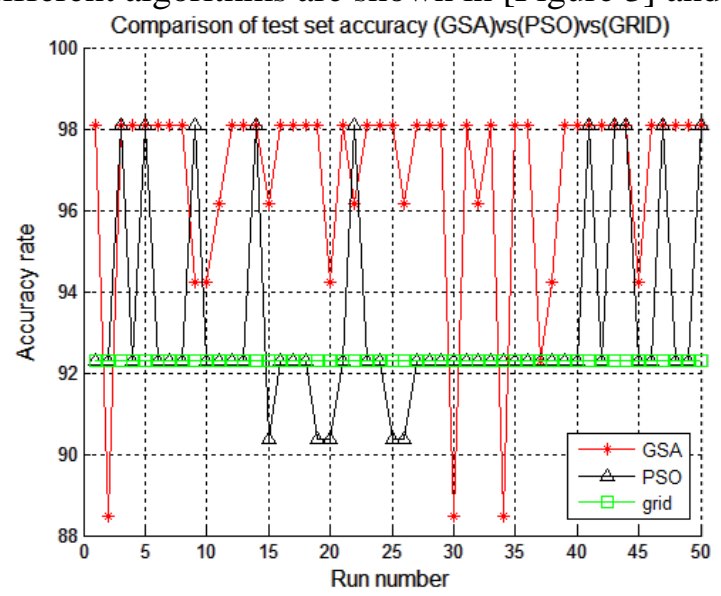

Figure 3. Comparisons of test set accuracy (GSA, PSO and GRID)

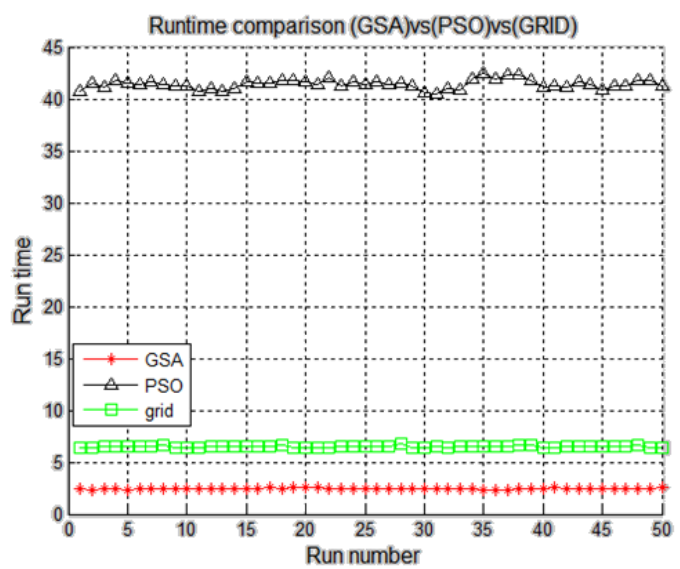

Figure 4. Comparisons of runtime (GSA, PSO and GRID)

According to [Figure 3], The correctness rate of the GRID-SVM algorithm in the prediction model reached $92.30769 \%$. After using PSO and GSA to optimize the SVM parameters, the prediction results of the prediction model are quite different. The accuracy of GSA-SVM is mainly concentrated at $98.0769 \%$, and the minority is $96.15385 \%, 94.23077 \%$ and $88.46154 \%$. The PSO-SVM discriminant rate is mainly concentrated at $92.30769 \%$. The average prediction accuracy of the two prediction models of PSO-SVM and GSA-SVM after 50 tests was $93.27 \%$ and $96.69 \%$. Figure 4 shows that GSA-SVM has the shortest execution time, and the execution time of PSO-SVM is much longer than the execution time of GRIDSVM and GSA-SVM. GSA-SVM has high performance in rice production discrimination, and the expected effect is good. Therefore, the use of mineral elements and GSA-SVM prediction model can achieve traceability of rice origin.

\section{Conclusion}

In this experiment, 154 samples of rice from the opposite side, Panjin, Wuchang, Yuanqu and Gongzhuling were analyzed by ICP-MS method, and 52 kinds of minerals such as Na, 
$\mathrm{Mg}, \mathrm{Al}, \mathrm{K}$ and $\mathrm{Ca}$ were detected in all samples. The elements below the detection line in the $1 / 2$ rice sample were subtracted from the experiment. The prediction model established by GSA-SVM is used to verify the sample data in the five regions of the prediction set. The average correct rate of multiple identification classification is $96.69 \%$, which is compared with the grid and PSO parameter optimization SVM identification classification. The execution speed is fast and the discrimination accuracy is high.

In summary, the mineral content can be used as a basis for judging the rice source in different regions of the three northeastern provinces. However, the current research is only for some regions, and some varieties of samples have been studied for the identification of geographical origin, which is not comprehensive. At the same time, the GSA-SVM algorithm is used to identify the origin, which is also affected by the premature phenomenon. Therefore, the main direction of the next research is how to improve the GSA-SVM algorithm and improve the stability of the model.

\section{Acknowledgements}

The work is Supported by Major Project of Heilongjiang Province Science and Technology Department(no.GA14B104), CAS Key Laboratory of Renewable Energy (no.Y907k81001).

\section{References}

[1] T. bosona and G. gebresenbet, "Food traceability as an integral part of logistics management in food and agricultural supply chain," Food Control, vol.33, no.1, pp.32-48, (2013)

[2] M. M. aung and Y. S. chang, "Traceability in a food supply chain: safety and quality perspectives," Food Control, vol.39, no.1, pp.172-184, (2014)

[3] M. Aceto, E. Robotti, M. Oddone, M. Baldizzone, G. Bonifacino, G. Bezzo, R.D. Stefano, F. Gosetti, E. Mazzucco, M. Manfredi, and E. Marengo, “A traceability study on the Moscato wine chain," Food Chemistry, vol.138, no.2-3, pp.1914-1922, ( 2013) DOI: 10.1016/j.foodchem.2012.11.019

[4] T. S. Pilgrim, R. J. Watling, and K. Grice, "Application of trace element and stable isotope signatures to determine the provenance of tea (Camellia sinensis) samples," Food Chemistry, vol.118, no.4, pp.921-926, (2010) DOI: 10.1016/j.foodchem.2008.08.077

[5] C. Benincasa, J. Lewis, E. Perri, G. Sindona, and A. Tagarelli, "Determination of trace element in Italian virgin olive oils and their characterization according to geographical origin by statistical analysis," Analytica Chimica Acta, vol.585, no.2, pp.366-370, (2007) DOI: 10.1016/j.aca.2006.12.040

[6] L. G. Van Der, J. L. Fischer, and P. P. Coetzee, "Multi-element analysis of south african wines and their provenance soils by icp-ms and their classification according to geographical origin using multivariate statistics," South African Journal of Enology and Viticulture, vol.31, no.2, pp.143-153, (2016) DOI: $10.1117 / 12.849762$

[7] B. Lu, N.Ma, X. Wang, and D. Zhang, "Tracing the geographical origin of soybeans based on inductively coupled plasma mass spectrometry (ICP-MS) analysis of mineral elements," Food Science, vol.39, no.08, pp.288-294, (2018)

[8] Silvia García-Ruiz, M. Moldovan, G. Fortunato, S.Wunderli, and J. Ignacio García Alonso, "Evaluation of strontium isotope abundance ratios in combination with multi-elemental analysis as a possible tool to study the geographical origin of ciders," Analytica Chimica Acta, vol.590, no.1, pp.55-66, (2007) DOI: 10.1016/j.aca.2007.03.016

[9] P.Cheajesadagul, C. Arnaudguilhem, J. Shiowatana, A. Siripinyanond, and J. Szpunar , "Discrimination of geographical origin of rice based on multi-element fingerprinting by high resolution inductively coupled plasma mass spectrometry," Food Chemistry, vol.141, no.4, pp.3504-3509, (2013) DOI: 10.1016/j.foodchem.2013.06.060 
[10] K. Ariyama, M. Shinozaki, and A. Kawasaki, "Determination of the geographic origin of rice by chemometrics with strontium and lead isotope ratios and multielement concentrations," Journal of Agricultural and Food Chemistry , vol.60, no.7, pp.1628-1634, (2012) DOI: 10.1021/jf204296p

[11] Y. Zhang, Z. Wang, Y. Zhang, W.Min, and Y.Wang, "The provenance traceability of rice based on the principal component analysis and discriminant analysis," Journal of the Chinese Cereals and Oils Association, vol.31, no.4, pp.1-5, (2016)

[12] K.H.Laursen, Mihailova, S.D. Kelly, V.N.Epov, S. Bérail, J.K. Schjoerring, O.F.X. Donard, E.H. Larsen, N. Pedentchouk, A.D. Marca-Bell, U. Halekoh, J.E. Olesen, and S.Husted, "Is it really organic?--multi-isotopic analysis as a tool to discriminate between organic and conventional plants," Food Chemistry, vol.141, no.3, pp.2812-2820, (2013) DOI: 10.1016/j.foodchem.2013.05.068

[13] P. Cheajesadagul, C. Arnaudguilhem, J. Shiowatana, A. Siripinyanond, and J. Szpunar, "Discrimination of geographical origin of rice based on multi-element fingerprinting by high resolution inductively coupled plasma mass spectrometry," Food Chemistry, vol.141, no.4, pp.3504-3509, (2013) DOI:10.1016/j.foodchem.2013.06.060

[14] H. Zhao, B. Guo, Y. Wei, and B. Zhang, "Multi-element composition of wheat grain and provenance soil and their potentialities as fingerprints of geographical origin," Journal of Cereal Science, vol.57, no.57, pp.391397, (2013) DOI: 10.1016/j.jcs.2013.01.008

[15] Q. Lili, S. Xuejian, Z. Dongjie, Z. Liyuan, R. Changqing, and L. U. Baoxin, "Tracing the geographical origin of sanjiang and wuchang rice grown in different years by near infrared spectroscopy," vol.39, no.16, pp.321327, (2018)

[16] J.Yuan, Z. Su, Y. Jia, Y. Zhang, and Z. Zhang, "Identification of rice leaf blast and nitrogen deficiency in cold region using hyperspectral imaging," vol.32, no.13, pp.155-160, (2016) DOI: 10.11975/j.issn.10026819.2016.13.022

[17] P. Zhao *, Y. Tang and Z. Li, "Wood species recognition with microscopic hyper-spectral imaging and composite kernel SVM,” Spectroscopy and Spectral Analysis, vol.39, no.12, pp.3776-3782, (2019)

[18] H. Zhang, C. Liu, J. Zhang, J. Han, Y. Chwn and L .Zheng, "Qualitative identification and quantitative analysis of maca adulteration based on multispectral imaging technology," Spectroscopy and Spectral Analysis, vol.40, no.1, pp.152-156, (2020) DOI: 10.3964/J.ISSN.1000-0593(2020)01-0152-05

[19] L. I. Ming, C. Fan, L. Meng, and L. I. Cui, "Near-infrared spectrum of coal origin identification based on lvq with svm algorithm," Spectroscopy and Spectral Analysis, vol.36, no.9, pp.2793-2797, (2016) DOI: 10.3964/j.issn.1000-0593(2016)09-2793-05

[20] J. Yang, F. Wu, "A modulation recognition method based on gravitational search optimizing neura network," Journal of xi'an university of posts and telecommunications, vol.24, no.4, pp.21-27+42, (2019) DOI: 10.13682/j.issn.2095-6533.2019.04.004

\section{Authors}

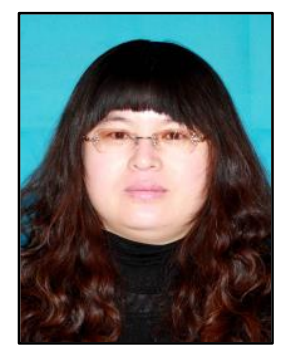

\section{Na Wang}

$\mathrm{Na}$ Wang is currently a lecturer at Heilongjiang Bayi Agricultural University. He received master's degree in Shenyang University of Technology. Her research work is the application of information technology in agriculture. 
Tracing the Geographical Origin of Rice Based on Mineral Elements and GSA-SVM

This page is empty by intention. 